Research Article

\title{
Quality of screen printing in knit fabric for different mesh count on semi solid design
}

\begin{abstract}
In semi solid design, the parameters of the quality of the printed fabric were color fastness, level of print detail, color difference, print coverage, saw-tooth effect, line sharpness etc. Actually, printed fabric quality was evaluated by these parameters. Again, print coverage, saw-tooth effect, line sharpness, etc. were examined by estimating different distances, angles etc. in printed fabric and these factors were compared with image positives. Mesh opening effect on the quality of screen printed fabric was investigated after printing the semi solid design on knit fabric using different mesh count screens and different types of the ink. To print semi solid design on knit fabric different types of ink as well as nonidentical mesh count was used. Then mesh screen out come on the design and form of printed fabric in screen printing was examined. For the evaluation of semi solid design effect there remains two different methods. The first one is visual assessment and another way is microscope observation. Here, to determine the probability of the amount of ink flowing by the screen, mesh opening area of every screen was considered and it was done from respective digital microscope images.
\end{abstract}

Keywords: mesh opening, mesh count, semi solid design, screen printing, printing quality
Volume 6 Issue 6 - 2020

\author{
Rasheda Begum Dina,' Md Zulhash Uddin,' \\ Ummul Khair Fatema ${ }^{2}$ \\ 'Department of Wet Process Engineering, Bangladesh University \\ of Textiles, Bangladesh \\ ${ }^{2}$ Department of Environmental Science and Engineering, \\ Bangladesh University of Textiles, Bangladesh
}

Correspondence: Rasheda Begum Dina, Assistant Professor, Department of Wet Process Engineering, Bangladesh University of Textiles, 92, Shaheed Taj Uddin Ahmed Avenue, Tejgaon, Dhaka-1208, Bangladesh, Tel +8801913518137,

Emaildina_butex@yahoo.com

Received: October 29, 2020 | Published: November 03, 2020
Abbreviations: MC, mesh count; GSM, gram per square meter, HW, high weight; LW, low weight

\section{Introduction}

Screen printing is one of the fundamental printing techniques that uses a woven mesh to pass printing ink in the suitable design. The mesh fabric forms open areas according to mesh count that pass printing paste onto fabric. The quality of the screen printing is determined by several particularities of the screen printing process such as the mesh type screen ruling, ink viscosity, raster spacing, etc. ${ }^{1}$ The amount of print paste passing through the screen can be controlled by the mesh (threads/inch) of the screen fabric. Generally, a coarse mesh allows more paste to pass through than a fine one. ${ }^{2}$

Mesh opening can be controlled by changing thread width and height. Higher mesh count screen allows less opening space than lower mesh count screen depending on the thread diameter of the mesh screen. Saw tooth effect is a very important parameter for determining printing quality .This is depended on opening space of mesh count and thread diameter.

The 'saw-tooth effect' is an almost inevitable consequence of the design area consisting of a regular array of threads and spaces. ${ }^{3}$

Synthetic polyester fabrics are the most useful material for screen printing. Strength of polyester fabrics is better than natural material .Polyester woven mesh can resist squeeze pressure and absorb very less amount of printing ink. These mesh screens offer increased process reliability and higher tensioning that is retained over large print runs and long periods of time.

Generally, there are three types of textile inks such as solventbased inks, water-based inks and plastisol inks. In textile printing water-based and plastisol inks are widely used. Water is used as the main solvent in water-based inks .Many water-based inks contain petroleum-based co-solvents to decrease the time and heat in the curing process.
Plastisol inks, commonly used for textile printing and especially for t-shirts, are a PVC-based ink composed of a clear, thick plasticizer fluid and PVC resin. Level of print detail is governed primarily by the mesh count, and the relationship of thread diameter to mesh opening. ${ }^{4}$

Screen printing is one of the most popular methods in the printing market. This method has long been the standard for knit fabric printing. A correct design with proper resolution, coverage, hand feel can be achieved by selecting the proper mesh count and ink system appropriately.

The research work was carried on printing under three mesh count screens for semi solid design with five types of ink to relate assessment of printing quality and effect of mesh count on cotton knit printed fabric.

\section{Materials and methods}

\section{Materials}

Fabrics: $100 \%$ cotton fabric of $1 \times 1$ rib structure, GSM 200 and 180 were collected from Micro Fiber Group. Fabric specifications are given in Table 3. Fabrics were pretreated in lab with the recipe given in Table 1 and Table 2. After pretreatment, fabrics were printed by the five different inks.

\section{Mesh fabrics}

Mesh fabrics of 43, 61 and 77 mesh count were purchased from Dysin-Chem Limited. Mesh specification is given in Table 4.

\section{Printing inks}

Five types of printing inks are used for the experiment. Three of these inks are water based, one is solvent based and another is plastisol based. Both solvent-based ink NYE 100 (black) and plastisol based ink ONP 124 (red, free from phthalate) are ready paste while rest of three inks named RYUDYE-W KN WHITE P-75 RYUDYE-W KN CLEAR P-76 (acrylic polymer), Stretch White 301-1 (acrylic resin) Clear 301C-J-1 and NEWTEX BIF New (pigment printing agent) are 
not ready paste. All inks were taken from Dysin Chemicals Ltd. The printing recipes are given in Table 5.

\section{Chemicals}

Chemicals for pretreatment: Having purchased Standard soap, Sequestering Agent INSA, Wetting Agent KS-90, Hydrogen Peroxide, Stabilizer, Alkali, acetic acid, Enzyme-DL, Anti-Creasing Agent CAN; CBA, Per Oxide Killer OEM chemicals from Orient Chem-Tex Limited were used for scouring and bleaching of the fabrics before printing according to the recipe given in Table 1 and Table 2.

\section{Chemicals for screen preparation}

Emulsion photo cure TXR, Adhesive SFX001, and catalyst SFX002 AT were purchased from Dysin-Chem Limited. Emulsion photo cure TXR was used during the coating of screen mesh fabric and Adhesive SFX001 and catalyst SFX002 AT were used during attachment of mesh fabric with the aluminum frame.

\section{Instrumentation}

Screen stretcher machine: The pneumatic stretching machine made by Murakami, Singapore was used for stretching mesh fabric before attaching to the aluminum frame.

Curing machine: For fixation of printing paste after printing process, NOR was used.

Tension meter: For recording tensions, a Murakami Tension Meter was used.

Light fastness tester: For light fastness testing, Microsol light fastness tester of James H.Heal, Halifax, England was used.

Screen drying machine: For drying screen after emulsion coating, screen Drying Machine, Murakami, was used.

Screen printing machine: For fabric printing, screen printing machine, Ltd. Shenzhen China, was used.

Viscometer: Viscometer, Brookfield, was used to measure the viscosity of printing paste.

Digital microscope: Digital microscope, with very quality resolution image sensor, made in China, was used for observing the microscopic view of mesh screen, emulsion coated mesh fabric, and printed area of cotton fabric.

Gyro wash machine: Gyro wash of James H. Heal Co. Ltd, Halifax, and English was used for wash fastness testing.

Crock meter: Digital Crock meter was used for rubbing fastness testing.

UV exposure: For exposing UV light on the image positive paper, Murakami was used for emulsion coated screen.

Spectrophotometer and color matching software: Data color 650 Spectrophotometer and color matching software made by USA was used for measuring color values.

Lab temperature humidity control chamber: Fang Yuan Instrument Co. Ltd, Shenzhen, China was used for conditioning printed sample.

\section{Methods}

Preparation of screen: Semi solid designs were selected and their film positive was created. For semi solid design, 43, 61 and 77 meshes count screens were used. The screen was attached with a frame by adhesive SFX001 and catalyst SFX002 AT 17 Newton per cm.
Screen was coated with photo cure TXR and dried, got film positive, aligned it to the screen, and exposed it with a screen-printing exposure unit for 30 seconds. After that screen was washed by normal water and dried at $55^{\circ} \mathrm{C}$.

\section{Pre-treatment (scouring and bleaching)}

Cotton fabric was pretreated by the recipe given in Table 1 .

By this treatment, actually, scouring and bleaching process were done.

\section{Printing}

At first, the screen and frame are joined with a tape. To block out any unwanted 'pin-holes' in the emulsion, it was very required to check.

Fabrics were softly glutinous at the top of the printing plate. The screen was settled on the machine. Printing paste was holding on the screen. Then the machine was started. Printing was done by continuous squeeze pressure as well as $45^{\circ}$ squeeze angle. There were thirty samples prepared by three mesh screens. For each screen was used to print on two unlike of fabric by five dissimilar print inks.

\section{Curing}

Curing was done for five minutes for addition of printing ink maintain the temperature at $150^{\circ} \mathrm{C}$.

\section{Weight measurement}

Printed and unprinted fabric was cut in a definite measurement for a certain design. The measurement was taken according to the printed area. Ink deposition weight was found by the unlike of printed and unprinted fabric weight. All the weights were taken by electronic balance. And it was done after conditioning the fabric for four hours at $65 \%$ relative humidity and $20^{\circ} \mathrm{C}$ temperatures.

\section{Color co-ordinates of printed sample}

The color coordinates of the samples were determined by dual beam reflectance spectrophotometer. Here color-matching software was used. ${ }^{5}$

\section{Printed fabric analysis under digital microscope}

At first, the Gaosuo software was installed on the computer. The digital microscope was kept with a stand and connected via wire to the USB port of the computer. A screen was opened on a computer. At first Camera size was selected to capturing the picture, there were five camera sizes.

In the research work one camera size $(640 \times 480$ pixels $)$ was used. The printed fabric was kept under the microscope and clicked the capture option to capture the image. When stop option was clicked, the capturing image was stopped. Then the picture was saved in the computer.

\section{Color fastness test}

Washing fastness: Washing fastness experiment was done following ISO 105 C02 method. ${ }^{6}$

Light fastness test: Light fastness trial was ended by ISO 105B02 method. $^{7}$

Rubbing fastness: Rubbing Fastness evaluation was carried out by ISO $105 \times 12$ method (Tables $1-5){ }^{8}$ 
Table I Pretreatment recipe

\begin{tabular}{lcll}
\multicolumn{2}{l}{ Pretreatment (scouring and bleaching) } \\
\hline Chemical name & Dosing & Quantity & Fabric Wt.45.8kg \\
\hline KS-90 & $1.30 \mathrm{~g} / \mathrm{l}$ & $0.390 \mathrm{~kg}$ & \\
INSA & $0.25 \mathrm{~g} / \mathrm{l}$ & $0.075 \mathrm{~kg}$ & \\
CAN & $0.65 \mathrm{~g} / \mathrm{l}$ & $0.0195 \mathrm{~kg}$ & $98^{\circ} \mathrm{C}^{\prime} 50 \mathrm{Min}$ \\
CBA & $0.65 \mathrm{~g} / \mathrm{l}$ & $0.195 \mathrm{~kg}$ & \\
Stabilizer & $0.22 \mathrm{~g} / \mathrm{l}$ & $0.066 \mathrm{~kg}$ & \\
Caustic soda & $1.80 \mathrm{~g} / \mathrm{l}$ & $0.540 \mathrm{~kg}$ & \\
Hydrogen per oxide $(50 \%)$ & $1.75 \mathrm{~g} / \mathrm{l}$ & $0.525 \mathrm{~kg}$ &
\end{tabular}

Table continue

\begin{tabular}{llll}
\hline Chemical name & Dosing & Quantity & Fabric Wt.45.8kg \\
\hline OEN & $0.30 \mathrm{~g} / 1$ & $0.09 \mathrm{~kg}$ & \\
DL & $0.25 \mathrm{~g} / \mathrm{l}$ & $0.115 \mathrm{~kg}$ &
\end{tabular}

Table 3 Types of fabric with specification

\begin{tabular}{llll}
\hline Fabric & Knit structure & GSM & Composition \\
\hline HG & RIB $(|\times|)$ & 200 & $100 \%$ cotton \\
LG & RIB $(|\times|)$ & 180 & $100 \%$ cotton \\
\hline
\end{tabular}

Table 4 Types of mesh with specification

Table 2 per oxide killing and enzyme treatment

\begin{tabular}{llll}
\hline Chemical name & Dosing & Quantity & FabricWt.45.8kg \\
\hline A.ACID & $0.80 \mathrm{~g} / \mathrm{l}$ & $0.24 \mathrm{~kg}$ & \\
\hline
\end{tabular}

\begin{tabular}{llll}
\hline Mesh count & Weave & Filament type & Raw materials \\
\hline 43 & Plain & Mono & Polyester \\
77 & Plain & Mono & Polyester \\
100 & Plain & Mono & Polyester \\
\hline
\end{tabular}

Table 5 Printing recipe

\begin{tabular}{llll}
\hline Ingredients & Ingredients composition & Used amount & Viscosity (cps) \\
\hline Water based ink & RYUDYE-W KNWHITE & 95000 \\
& P-75 (=40\%) & $90 \%$ & \\
& RYUDYE-W KN CLEAR & & \\
& P-76(=60\%) & & \\
RYUDYE-W COLOUR & - & $10 \%$ & \\
Water based ink & StretchWhite 30I-I(=40\%) and Clear 30I & $90 \%$ & 130000 \\
Neo Color pigment & C-J-I(=60\%) & & \\
Fixer F & - & $8 \%$ & \\
(or Fixer N) & - & $2 \%$ & \\
Water based ink (NEWTEX BIF) & - & & \\
Printing Color & - & $90 \%$ & \\
Solvent based ink (NYEI00) & Ready paste & $10 \%$ & \\
Plastisol based ink (ONP I24) & Ready paste & $100 \%$ & 7800 \\
\hline
\end{tabular}

\section{Results and discussion}

\section{Calculation of open area percentage of mesh count fabric}

For calculating the open area, it took $66 \mathrm{~mm}^{2}$ area of mesh fabric under the microscope $(640 \times 480$ pixels $)$. The number of open rectangles was counted and the percentage of the open area was calculated by the following formula.

$$
\begin{gathered}
\text { Average rectangle area }=\frac{\sum(\text { Total open rectangle area })}{\text { Number of open rectangle area }} \\
\text { Percentage of open area }=\frac{\text { Average open rectangle area }}{36} \times 100
\end{gathered}
$$

Total open rectangle area=average open rectangle area $\times$ total number of open rectangle area.

The percentage of open area for different mesh count is given in Table 6.
The order of percentage of opening area was as below:

43 mesh count screen $>61$ mesh count screen $>77$ mesh count screen

From Figure 1a, there were five lines of open rectangles and each line had five open rectangles in mesh count 43. In one line the area of open rectangles were as below:

The area of open rectangles $\left(\mathrm{mm}^{2}\right)$

$\begin{array}{lllll}0.38 I & 0.384 & 0.4 I & 0.4 I & 0.384\end{array}$

The average of open rectangles area was $0.3938 \mathrm{~mm}^{2}$ and total number of open rectangles was 25 . Total open area was $9.845 \mathrm{~mm}^{2}$.

From Figure 1b, there were eight lines of open rectangles and each line had twelve open rectangles in mesh count 61 . In one line the area of open rectangles were as below: 
The average of open rectangles area was $0.1056 \mathrm{~mm}^{2}$ and total number of open rectangles was 64 . Total open area was $6.67 \mathrm{~mm}^{2}$.

From Figure 1c, there were ten lines of open rectangles and each line had ten open rectangles in mesh count 77 . In one line the area of open rectangles were $0.058,0.04,0.067,0.056,0.067,0.056,0.024,0$ $.029,0.048,0.064 \mathrm{~mm}^{2}$ and The average of open rectangles area was $0.0509 \mathrm{~mm}^{2}$ and total number of open rectangles were 100.Total open area was $5.09 \mathrm{~mm}^{2}$.

Table 6 Percentage of open area of mesh fabric in different screen count

\begin{tabular}{lllllll}
$\begin{array}{l}\text { Mesh } \\
\text { count }\end{array}$ & $\begin{array}{l}\text { Total number of open } \\
\text { rectangles at 6 } \mathbf{6} \mathbf{m m}^{2}\end{array}$ & $\begin{array}{l}\text { Average } \\
\text { rectangle area }\end{array}$ & $\begin{array}{l}\text { Total } \\
\text { area }\end{array}$ & $\begin{array}{l}\text { Percentage of } \\
\text { open area }\end{array}$ & $\begin{array}{l}\text { Average yarn } \\
\text { width }\end{array}$ & $\begin{array}{l}\text { Average yarn } \\
\text { height }\end{array}$ \\
\hline 43 & 25 & 0.3938 & 9.845 & 27.34 & 0.488 & 0.64 \\
61 & 64 & 0.127 & 6.67 & 18.77 & 0.375 & 0.34 \\
77 & 100 & 0.0509 & 5.059 & 14.04 & 0.193 & 0.243
\end{tabular}

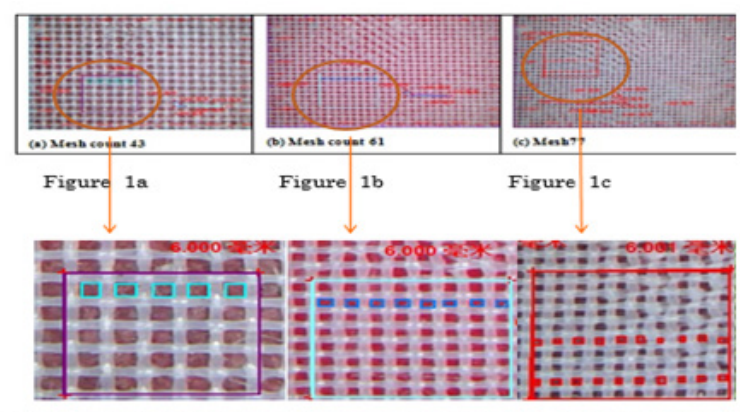

Figure I Images of mesh fabrics under microscope $(640 \times 480$ pixels).

Visual assessment of printed fabric: We categorized the printed fabric, excellent (rating-7), very good (rating-6), good (rating-5), moderate (rating-4), bad (rating-3), very bad (rating-2), worst (rating-1) in background coverage, hand feel and print detail for visual assessment (Figures 2a \& 2b) (Table 7).

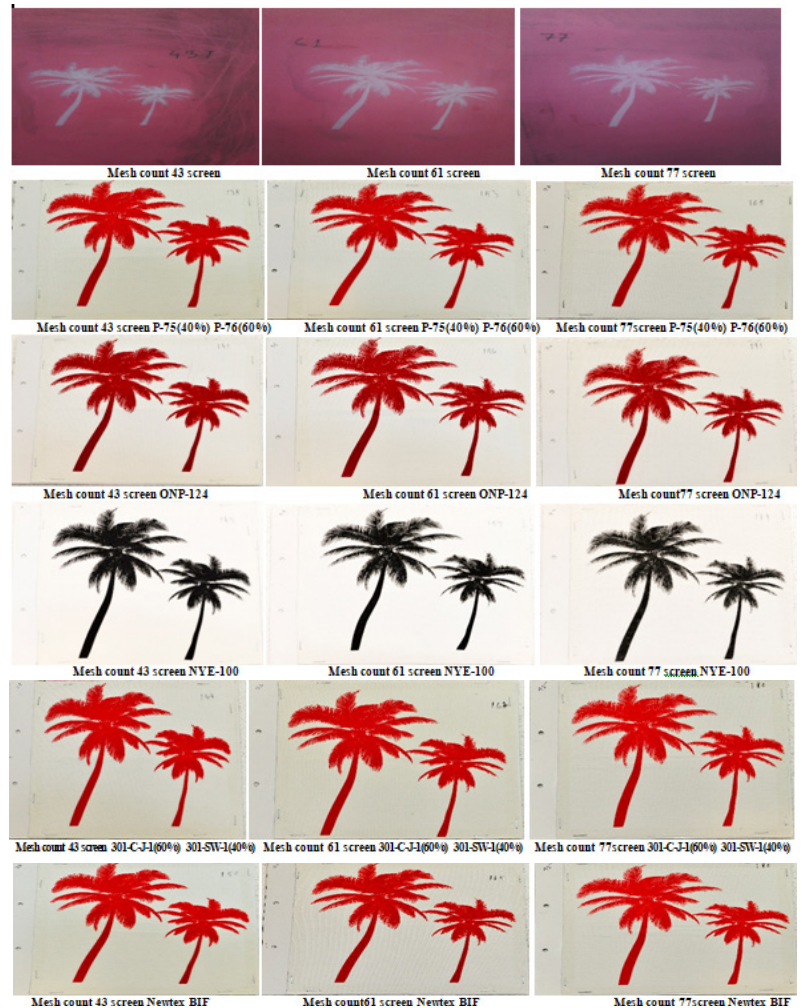

Figure $\mathbf{2 a}$ Semi solid design printed fabric (low GSM) with different mesh count screen by different inks.

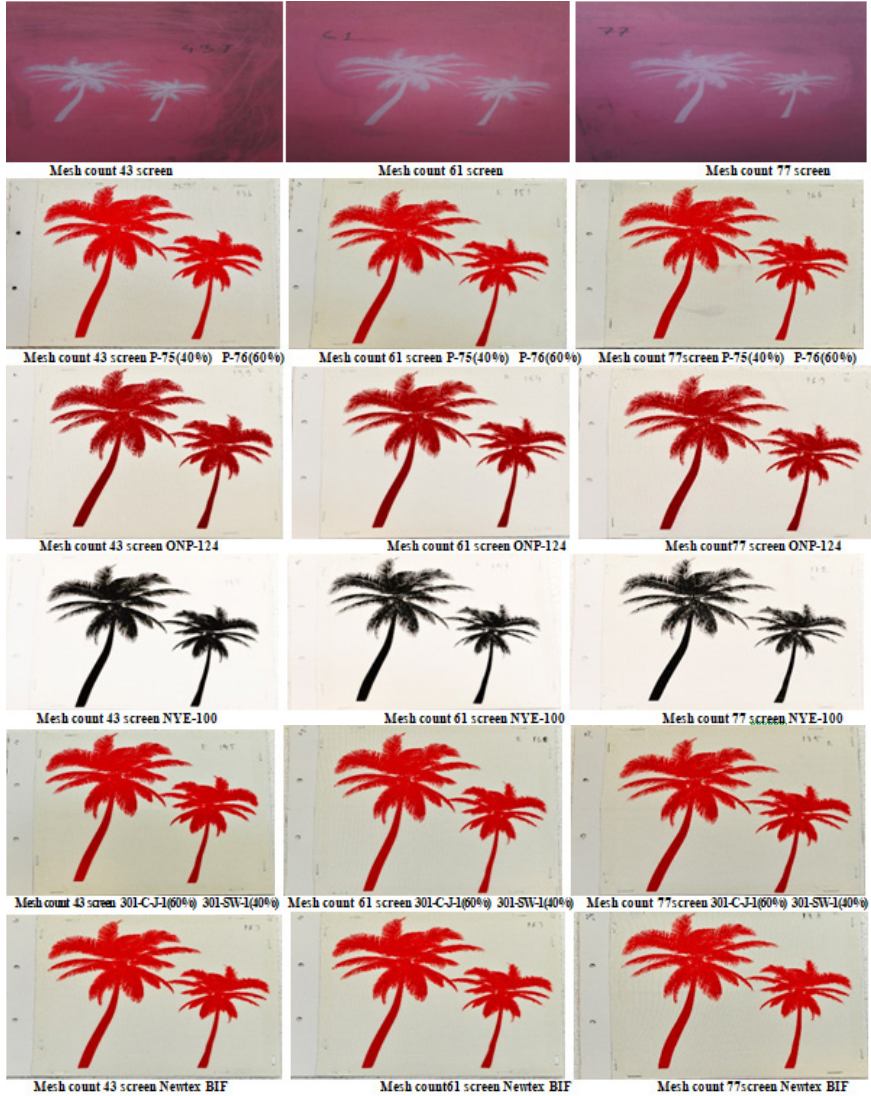

Figure 2b Semi solid design printed fabric (high GSM) with different mesh count screen by different ink.

From Figure 3, it was found that the background coverage was excellent but decrease print detail and also increased bad hand feelings as the ink was deposited in a high percentage for higher mesh opening screen and print detail was good for high mesh count screen (Figure 4). From Figure 5, background coverage decreases when mesh opening area increases.

Ink deposition on printed fabric: The samples were cut after conditioning at temperature $20^{\circ} \mathrm{C}$ and 65 percent relative humidity of printed and unprinted fabric. Then sample weight $\left(10^{\prime \prime} 9\right)$ was measured by electronic balance.

The ink deposition percentage was calculated by the following formula.

Percentage of ink deposition $=\frac{\text { printed fabric weight-unprinted fabric weight }}{\text { unprinted fabric weight }} \times 100 \%$ 
Ink Deposition order was ONP $>$ CJ-1-301, SW-1-301 $>$ P75, P76>Pigment $>$ NYE. It found that more paste was deposited on printed fabric in high GSM fabric than lower GSM. By high open area

Table 7 Quality of semi solid printed fabric (visual assessment) mesh count screen as the more open area pass more ink. The order was $43 \mathrm{MC}$ screen $>61 \mathrm{MC}$ screen $>77 \mathrm{MC}$ screen (Figure 6).

\begin{tabular}{lllll}
\hline Ink Name & Mesh count & Background coverage & Print detail & Hand feel \\
\hline P-75(40\%) & 43 & Good & Very bad & Very bad \\
P-76(60\%) & 61 & Moderate & moderate & Moderate \\
& 77 & Moderate & Moderate & Moderate \\
ONP-124 & 43 & Good & Very bad & Very bad \\
& 61 & Moderate & moderate & Moderate \\
& 77 & Moderate & Moderate & Moderate \\
NYE-100 & 43 & Moderate & bad & Very bad \\
& 61 & Bad & moderate & Moderate \\
& 77 & Bad & Moderate & Moderate \\
$30 I-C-J-I(60 \%)$ & 43 & Good & Very bad & Very bad \\
$30 I-S W-I(40 \%)$ & 61 & Moderate & moderate & Moderate \\
& 77 & Moderate & Moderate & Moderate \\
Newtex BIF & 43 & Good & bad & Moderate \\
& 61 & Moderate & moderate & Good \\
& 77 & Moderate & Moderate & Good \\
\hline
\end{tabular}

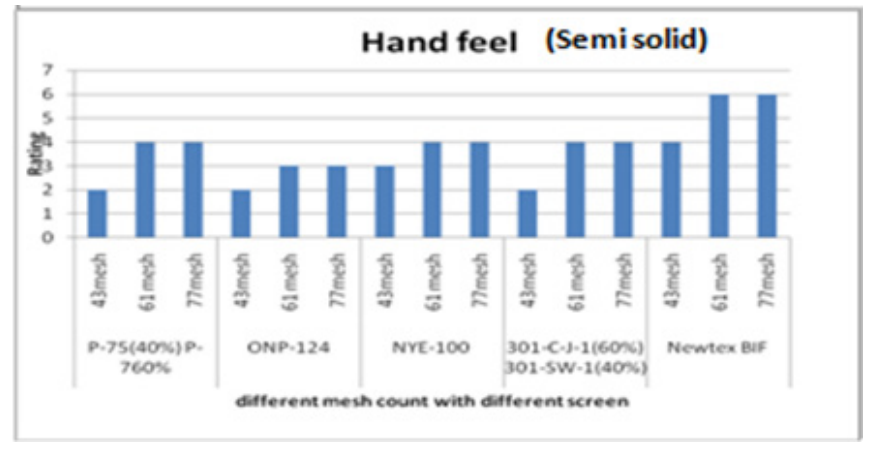

Figure 3 Hand feel in semi solid design.

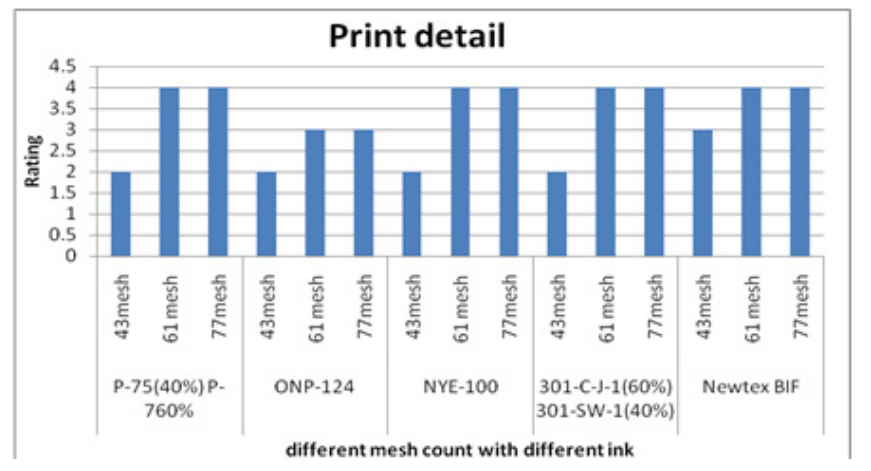

Figure 4 Assessment for print detail in semi solid design.

\section{Analysis of semi solid design under microscope}

For semi solid design, 43, 61 and77 mesh count fabric were used as print screen. From the top of the big tree a portion was selected for analyzing under the microscope as like Figure 7 .In the figure, it was seen several tree leaf lines. For the overlapping of leaf lines, it was created open area indicated by the square label, leaf line angle was indicated by the diamond label and distance was indicated by the circle label.

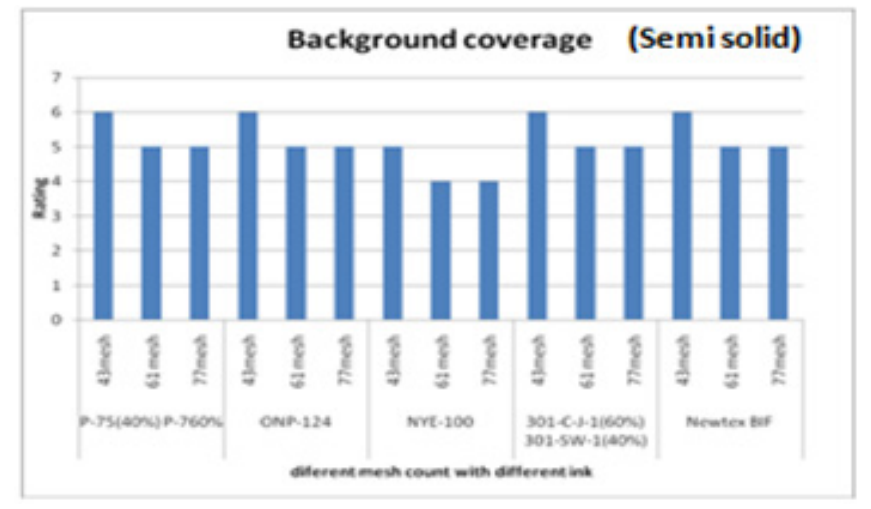

Figure $\mathbf{5}$ Visual assessment for background coverage in semi solid design.

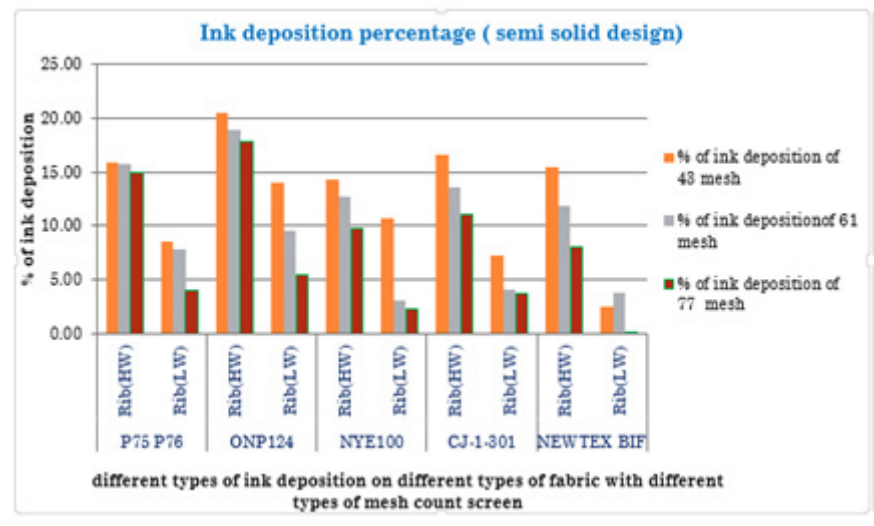

Figure 6 Ink deposition percentages (semi solid design). 


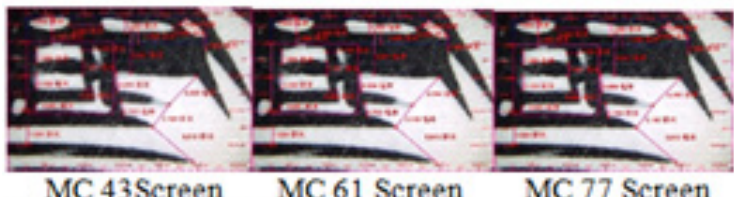
Image Positive of Semi solid Design

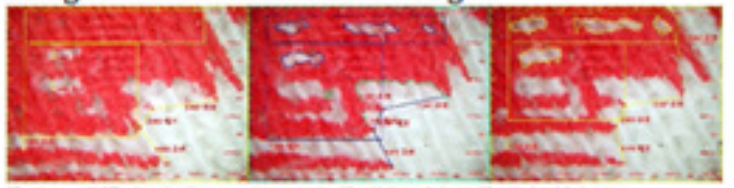

Printed Fabric by using ink P-75 $(40 \%)$ P-76(60\%)

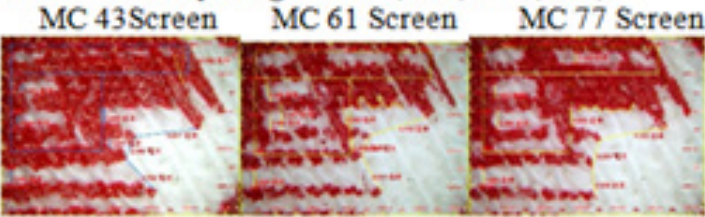

MC 43Screen MC 61 Screen MC 77 Screen

Printed Fabric by using ink ONP124

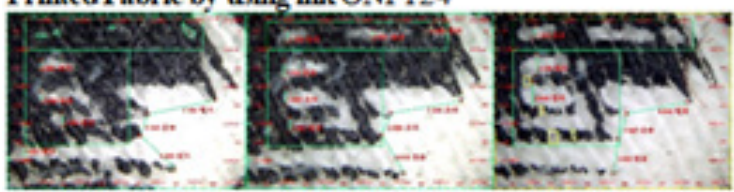

MC 43Screen

MC 61 Screen

MC 77 Screen

Printed Fabric by using ink NYE-100

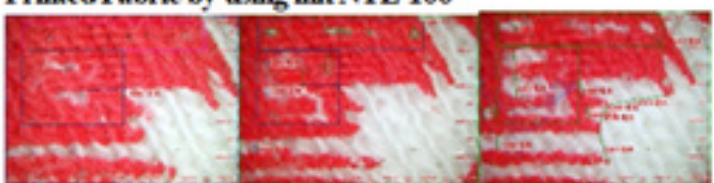

MC 43Screen MC 61 Screen MC 77 Screen Printed Fabric by using ink 301-C-J-1 $60 \%$ ) 301-SW-1(40\%)

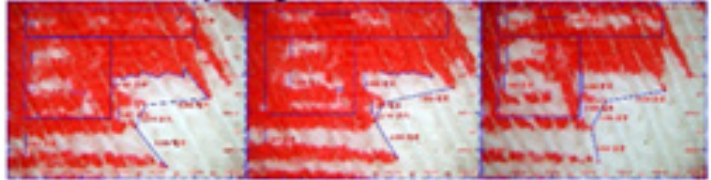

MC 43Screen MC 61 Screen MC 77 Screen Printed Fabric by using ink NEWTEX BIF

Figure 7 Printed fabric for semi solid deign under microscope $(640 \times 480$ pixels).

Five commercial pastes had been tested. Two different leaf lines distant were observed under the digital microscope that were 3.04, $5.168 \mathrm{~mm}$ and the gap between the lines was 1.703 and $2.20 \mathrm{~mm}$ respectively. The line resolution was evaluated from incomplete line distance with complete line distance at the image positive. It can be noted that the edges of the printed lines looked spread out the paste. The line distance 3 and distance 4 were $1.081 \mathrm{~mm}$ and $2.443 \mathrm{~mm}$ with the angle $84.222^{\circ}$ and $43.256^{\circ}$ in the printed fabric with P-75, D-76 print ink under 43 mesh screens. The both lines were found in zero gaps due to the large open area in the screen. With the increase of mesh count it was observed from Table 8, the distance of leaf lines was decreased but the gap between the lines was increased by 61 meshes. Whereas both distance and gap of line increased further increasing of mesh like 77. It was seen almost similar order of change in distance in printed fabric by 43,61 and 77 mesh fabric by five ink system. The order was $77>43>61$. On the other hand the leaf lines angell and angle 2 were observed $94.411^{\circ}$ and $43.264^{\circ}$ respectively (Figure 8 ) by the P-75, D-76 ink system which were enough larger than negative angle i.e., $20.727^{\circ}$ and $13.894^{\circ}$ respectively (Figure 9). But with the increase of mesh count like 61 it was observed the value of angle was $81.254^{\circ}$ and $40.282^{\circ}$ respectively (Figure 10). Further increasing of mesh count like 77 it showed the value such as $48.233^{\circ}$ and $26.685^{\circ}$ respectively (Figure 11). Due to the change of mesh the angle decreased gradually in an order $43>61>77$.

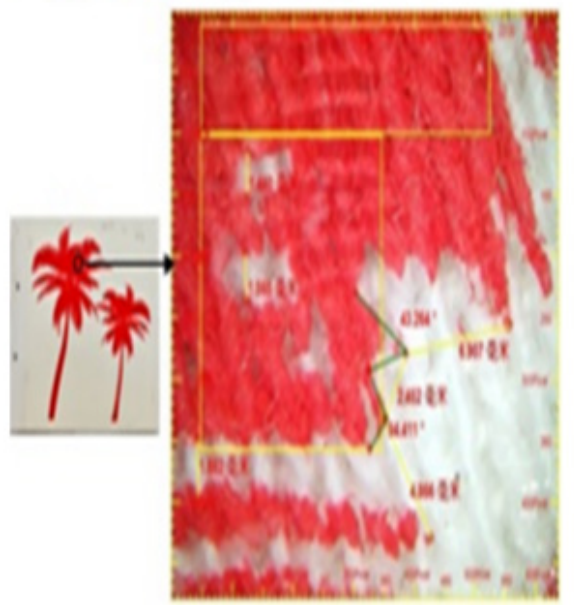

Figure 8 Image of semi solid design printed fabric using 43 mesh count screen $(640 \times 480$ pixels).

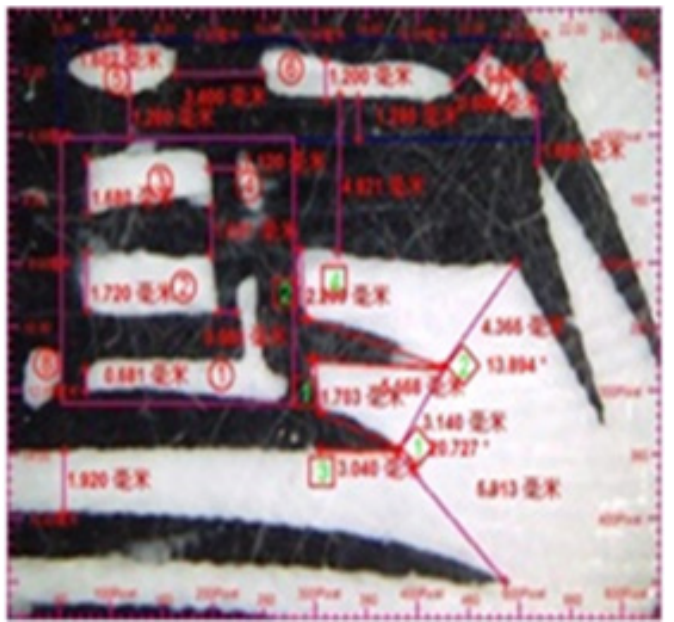

Figure 9 Image positive of semi solid design (640×480 pixels).

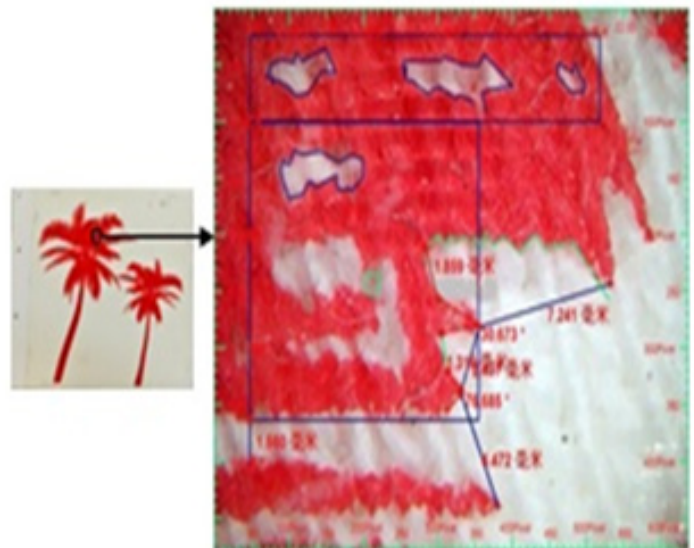

Figure 10 Image of semi solid design printed fabric using 61 mesh count screen $(640 \times 480$ pixels $)$. 


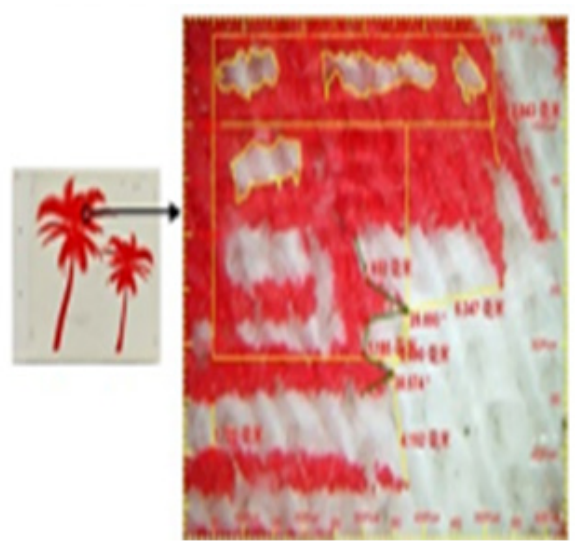

Figure I I Image of semi solid design printed fabric using 77 mesh count screen $(640 \times 480$ pixels $)$.
Even though it was expected that with the increase of mesh, the angle was supposed to decrease to a certain extent, but the result was not a satisfactory one. Therefore to achieve the target, the mesh count should have been increased. The printed fabric open area dimension was nearer to image open area at high mesh 77 but decrease gradually by 61 and 43 meshes (Figure 7).

From Table 8, it was found that accuracy of printing was better for higher mesh count with lower opening area by different ink deposition.

From Figure 12, internal distance was minimizing and external distance was maximizing in low mesh count.

From Figure 13, angle1 and angle2 are increased in 43 mesh count screen and lost line sharpness.Angle1 and angle 2 are decreased gradually for 61 and $77 \mathrm{mesh}$ count screens but not accurate like image positive. It needs further increase of mesh count of screen.

From Figure 14, it was observed that saw tooth effect decreased with the increase of MC. Outer line sharpness was almost similar to design for high MC.

Table 8 Different distance and angle measurement in semi solid design Printed fabric with different ink

\begin{tabular}{lllllll}
\hline Design: semi solid & Angle I & Angle2 & Distance I & Distance2 & Distance3 & Distance4 \\
\hline Positive (Image) & 20.727 & 13.894 & 1.73 & 2.209 & 3.04 & 5.168 \\
\hline
\end{tabular}

\begin{tabular}{llllllll}
\hline Negative & Mesh count & Angle I & Angle2 & Distance I & Distance2 & Distance3 & Distance4 \\
\hline P-75 D-76 & 43 & $94.4 I I$ & 43.264 & 0 & 0 & 1.081 & 2.443 \\
& 61 & 76.87 & 30.675 & 1.319 & 1.859 & 0.096 & 2.04 \\
& 77 & 38.574 & 28.893 & 1.185 & 1.932 & 2.04 & 2.725 \\
ONP-I24 & 43 & 54.95 & 35.884 & 1.211 & 0.862 & 1.602 & 2.922 \\
& 61 & 51.5 & 34.8 & 1.255 & 1.709 & 0.934 & 2.481 \\
& 77 & 39.42 & 30.39 & 1.582 & 1.902 & 1.64 & 3.001 \\
NYE-100 & 43 & 73.3 & 51.507 & 0.645 & 1.598 & 1.322 & 2 \\
& 61 & 71.56 & 36.44 & 1.441 & 1.897 & 0.84 & 1.52 \\
& 77 & 23 & 31 & 2.006 & 2.07 & 1.161 & 2.201 \\
CJ-I-30I & 43 & 61.649 & 47.866 & 0 & 0 & 2.04 & 2.88 \\
SW-I-30I & 61 & 59.127 & 36.4 & 1.106 & 1.093 & 1.56 & 2.321 \\
& 77 & 50.092 & 24.972 & 1.608 & 1.886 & 1.561 & 2.363 \\
PIGMENT & 43 & 84.226 & 43.256 & 0 & 1.485 & 1.602 & 2.32 \\
& 61 & 81.254 & 40.282 & 0 & 1.503 & 1.081 & 2 \\
& 77 & 48.253 & 26.685 & 0.573 & 2.169 & 1.882 & 2.774 \\
\hline
\end{tabular}

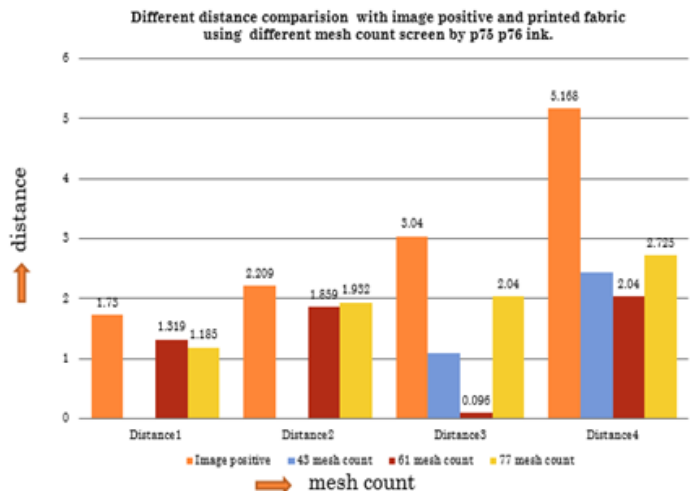

Figure 12 Different distance comparison with image positive and printed fabric.

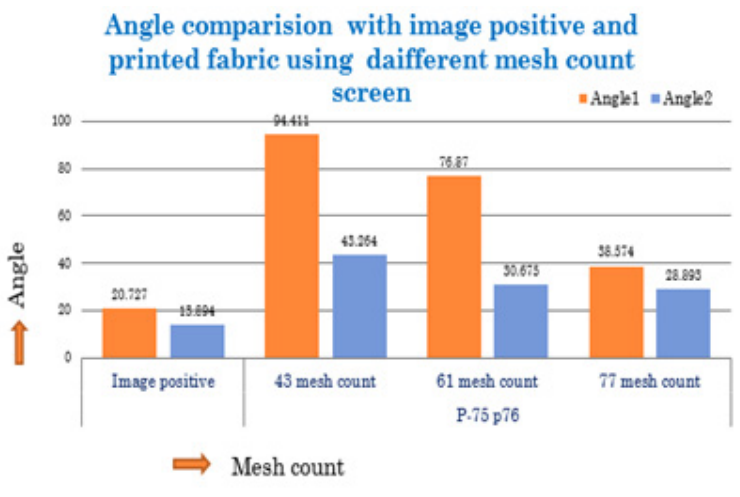

Figure I 3 Angle comparisons with image positive and printed fabric. 

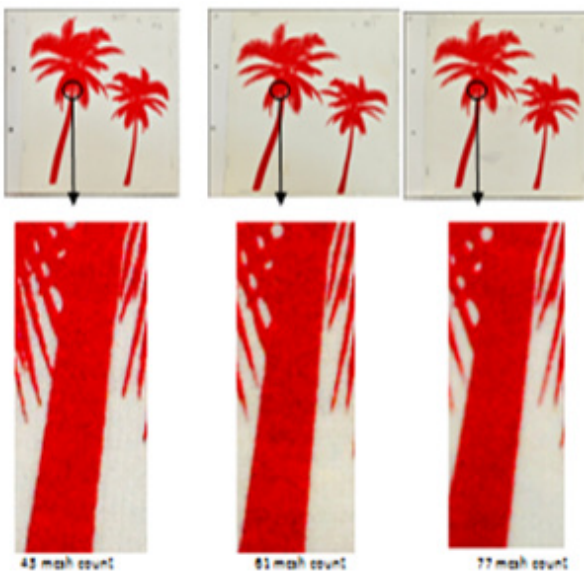

Figure I4 Saw tooth effect in semi solid design.

\section{Color difference of dissimilar printed fabric with various mesh count screen}

From the Figure 15, color difference was found with the change of the screen mesh count. With the higher mesh count screen, printed fabric was lighter in print than the lower mesh count screen.

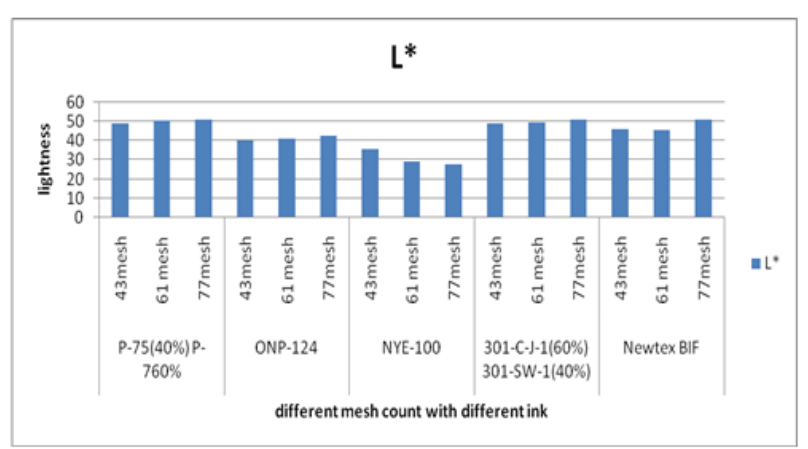

Figure 15 Lightness difference of different printed fabric under different mesh count.

\section{Color fastness performance}

Washing fastness and light fastness experiment of printed fabric under dissimilar mesh count screen with various inks were performed.

\section{Washing fastness}

Change of wash fastness with the change of mesh count was not remarkable (Figure 16). There was no significant change of light fastness with the change of mesh count.

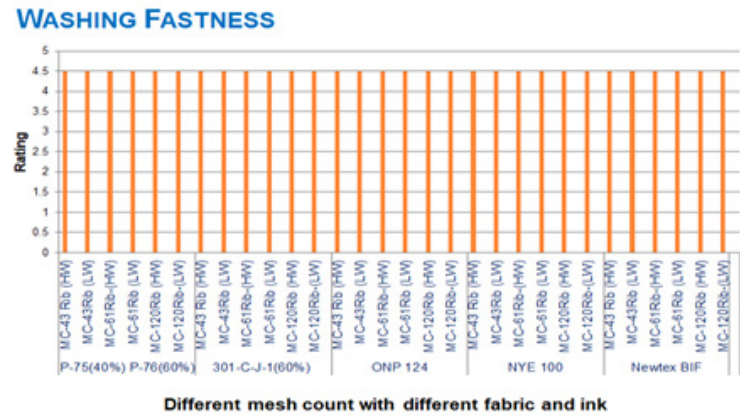

Figure I 6 Washing Fastness of different printed fabric under different mesh count with different ink.

\section{Light fastness}

Change of light fastness with the change of mesh count was negligible (Figure 17).

\section{LIGHT FASTNESS}

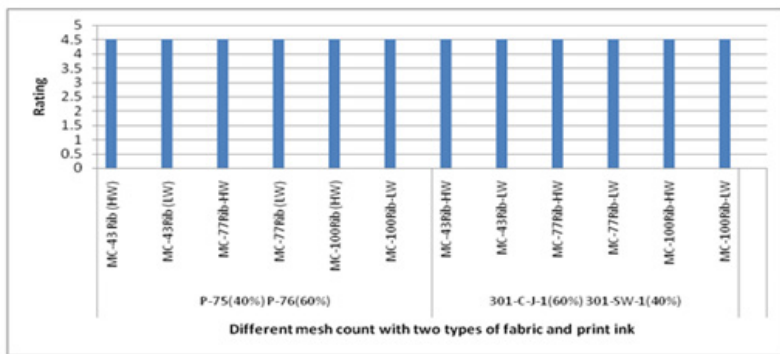

Figure 17 Light Fastness of different printed fabric under different mesh count with different.

\section{Rubbing fastness}

Change of rubbing fastness with the change of mesh count was negligible (Figure 18).

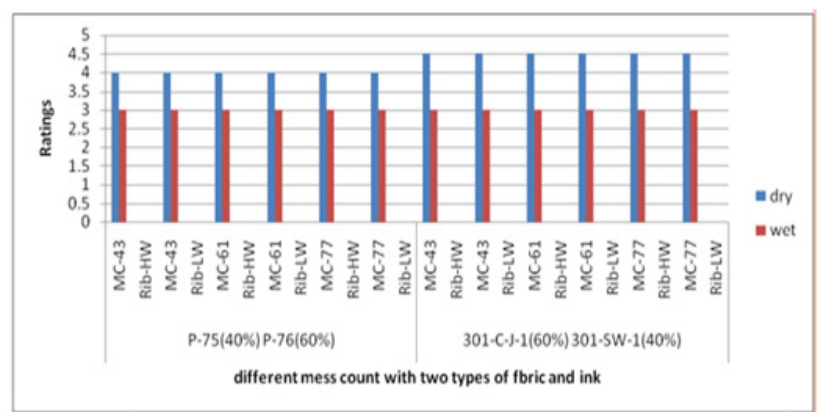

Figure I 8 Rubbing Fastness of different printed fabric under different mesh count with different ink.

\section{Conclusion}

The project work was carried to determine the quality of the printed fabric after printing with different mesh opening screen on semi solid design of the knit fabric.

It was determined that more ink was deposited on high GSM fabric with compare to the lower GSM fabric and percentage of ink deposition amount was larger for high viscous paste with compare to the lower one.

The result of using lower mesh opening screen was far better in printed fabric than higher mesh opening screen based on varieties of inks. On the other hand, the higher mesh opening area results in good background coverage in printed fabric. Print detail was not satisfactory in the higher mesh opening screen. Saw tooth effect was prominent in lower mesh count screen. The accuracy in line size and sharpness were nearer to image positive in higher mesh count screen. The printing quality was better in higher mesh count screen than the lower one. Wide range of mesh count screen may be tested for the design and this was the limitation of the thesis.

\section{Acknowledgments}

I would like to express my acknowledgements to Orient-Chem Ltd., Dysin-Chem Ltd. \& Dysin International Ltd for their strong support in different aspects of the thesis work. 


\section{Funding}

None.

\section{Conflicts of interest}

There is no conflict of interest in publishing articles according to the author's declaration.

\section{References}

1. Viorica C, Jana C, Emilia B, et al. The study of the screen printing quality depending on the surface to be printed. MATEC Web of Conferences; 2018 .

2. Leslie W C Miles. Textile printing. 2nd edn. p. 21.
3. Leslie W C Miles. Textile printing. 2nd ed. pp:44-45.

4. Rasheda Begum D, Zulhash U, UmmulKhair F. Effect of mesh opening on solid design and quality of screen printing in knit fabric. Journal of Textile Engineering \& Fashion Technology. 2020.

5. Author D Broadbent. Basic principle of textile coloration. Society of Dyers and Colorists; 2001:460-462.

6. ISO 105-C02. Textiles: Test for colorfastness part c02, color fastness to washing. 1994.

7. ISO 105-B02. Test for Color Fastness to artificial light: Xenon arc fading lamp test. 1994.

8. ISO 105-X12. Textiles: Test for color fastness. Part X12, color fastness. 1993. 